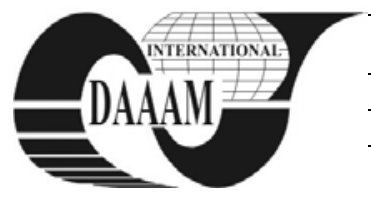

\title{
DETERMINING THE ORGANIC MICROPOLLUTANTS THROUGH THE GAS CHROMATOGRAPHY METHOD
}

\author{
TOPLICEANU, L[iliana]; BIBIRE, L[uminita] \& GHENADI, A[drian] S[telian]
}

\begin{abstract}
The complex technologies for producing synthetic industrial products cause insidious pollution phenomena. The determination of theses requires high performance methodologies and techniques. One of the most performant methods of this type is the gas chromatography. This paper presents the results achieved after the analysis of organic micropollutants in the water of an emissary, down the river from the point where wastewater was discharged from two process industry plants
\end{abstract}

Key words: chromatograph, wastewater, organic micropollutants

\section{INTRODUCTION}

The fundamental element causing the birth and the maintenance of life on earth is the water, a limited and vulnerable natural resource. Water is the raw material for productive activites, a source of energy and a means of transport, a determining factor in maintaining the ecological balance. Between the development of the human society and the environment there is a functional relationship represented as follows: $\mathbf{Y}_{\mathbf{i}}=\mathbf{f}\left(\mathbf{X}_{\mathbf{i}}\right)$ where $\mathbf{Y}_{\mathbf{i}}$ is the ecological demand, and $\mathbf{X}_{\mathbf{i}}$ is the economic growth. The ecological demand refers to the pressure imposed on the ecosystem. When this pressure is higher than the self-adjusting capacity of the ecosystem, the environment suffers an inevitable pollution which could have devastating effects (Stefanescu, 2003).

\section{WATER POLLUTION}

Water pollution is the contamination of water with substances that alter or even destroy the natural functions of the ecosystem. In other words, water polution is any physical, chemical or bacteriological modification or a natural radioactivity level over the admissible level which is directly or indirectly caused by the human activities (McNaught, 1997).

\subsection{Polluting factors}

The quality of water is significatly influenced by:

* the industrial development and the promotion of certain polluting production technologies;

* the use of fertilizers and pesticides in agriculture (diffuse pollution), phenomenon which is difficult to prevent;

* the noncorrelation of the increased production capacity and of the urban development with the updating of the sewage system and the water treatment stations;

* the improper use of the existing water treatment plants;

* the lack of an organized system for the collection, storage and management of industrial (Pavia, 2006).

\section{WATER CONTAMINATION WITH ORGANIC MICROPOLLUTANTS}

Organic micropollutants are chemical compounds which are part of the biocides. They are products containing one or more active substances and which have the role of preventing, deterring, distroying or controlling the action of any harmful organism, through chemical or biological methods. Biocides are used in various fields including: the food industry, cosmetics, the textile and leather industry, the wood industy, in making fodder, rubber, lacquers and dyes. These products are divided into four groups:

* group I includes disinfectants and products used for the human and veterinary hygiene, in the food industry, in preparing fodder, in treating the water;

* group II includes fungicides used for the treatment of wood, leather, fibers, rubber, in masonry, in cooling installations, in preventing the sedimentation of silt;

* group III includes pesticides, insecticides, herbicides used in fighting diseas and pests;

* group IV includes products used as food preservatives, antibiodermic products, fluids used in embalmment.

Used in normal conditions, these products should be highly efficient, without producing harmful effects on the human or animal body, and not affecting the environment. In fact, however, these substances are among the most potentially dangerous ones, since they could cause serious disorders and disease such as the cancer (Gerardi, 2003).

\subsection{The effects of the contamination with oraganic micropolluntants}

The presence of organic micropoluntants in water leads to the modification of its quality, with harmful effects on the water flowers and fauna as well as on the human body. These effects consist in modifications of the organoleptic parameters, the chemical contamination of the aquatic fauna, the chemical and bacteriological contamination of the agricultural products, the distruction of the microbian flora of the water, facts which lead to a dicrease in the self-defence capacity against different poluttants which may apear at a certain moment.

The chemical and the biological degradability of the micropollutants are extremely varied. Thus, while some micropollutants live up to a few weeks, others live up to a few months - the fungicides and the herbicides - and others up to 10 years - the organochlorine pecticides (DDT). Some micropollutants are contained and even decomposed during the water treatment processes, but others pass practically unchanged.

\section{CHROMATOGRAPHIC ANALYSIS OF THE WATER CONTAMINATION}

Several chemical and instrumental methods of analysis are used to identify the organic micropolluntants: evaporation, ultrafiltration, foaming, extraction, ionic excenge, activated carbon adsorption, aluminum oxide adsorption, adsorption in active slit, precipitation with iron or aluminum salts, gas cromatography, spectrophotometry etc.

Of all the analysis methods listed above, the most recommanded are the last two, since they offer much higher 
selectivity and accuracy compared to the other metdods. We must also take into consideration the fact that the substances discussed have a complex chemical structure, and their concentration in the water at a certain moment varies very much. Thus, complex methods are required for the analysis, methods which should allow us to distinguish the substances even if they are in very small concentrations.

In the case of organic micropolluntants, the identification and analysis method recommended is the chromatographic method, more exactly the gas chromatography (Pavia, 2006).

Chromatography consists in the adsorption of a complex mixture of substances on an adsorbent material, followed by the successive desorption of the different components of the mixture. They are distributed on two phases, a stationary one and a mobile one. The stationary phase is a nonvolatile liquid or an adsorbent solid, immobilized or not on a solid surface which has the role to separate the constituents of a mixture based on the different solubility, and the different adsorption. The mobile phase consists in the solvent used to elute the compounds of the mixture. Thus, when the mobile phase passes through the chromatographic column there is a migration, at different speed, of the compounds in the mixture subjected to the separation. The separation process is achieved based on the specific physical interactions which appear among the molecules of the sample analyzed and the stationaruy phase. When leaving the column, the compounds of the substance subjected to the analysis are detected by a physico-chemical analyzer which is able to give a signal proportional to the mollecular mass or to the concentration of the solution in the mobile phase (Nascu, 2009; *** Chromatography, 2010).

\subsection{Experimental research}

The experimental research was performed using a cromatograph, the functional diagram of which is presented in fig. 1. The mobile phase passes through a flow mesurement and adjustment device and gets into the device in order to introduce the sample. Here, the sample is taken by the mobile phase and transported through the chromatographic column where the compound separation takes place. The chromatographic column is placed in a thermoregulated container, so that optimal temperature conditions are created. The separate compounds pass through the detector, where each compound is marked by a specific signal. These signals are recorded using a recording device or they give the start signal for a data system which allows us to proces and store the results.

In order to determine the extent of the micropollution, samples were taken from the river Bistrita, close to the place where treated wastewater is discharged from two companies which work in the field of chemical fertilizers and cellulose.

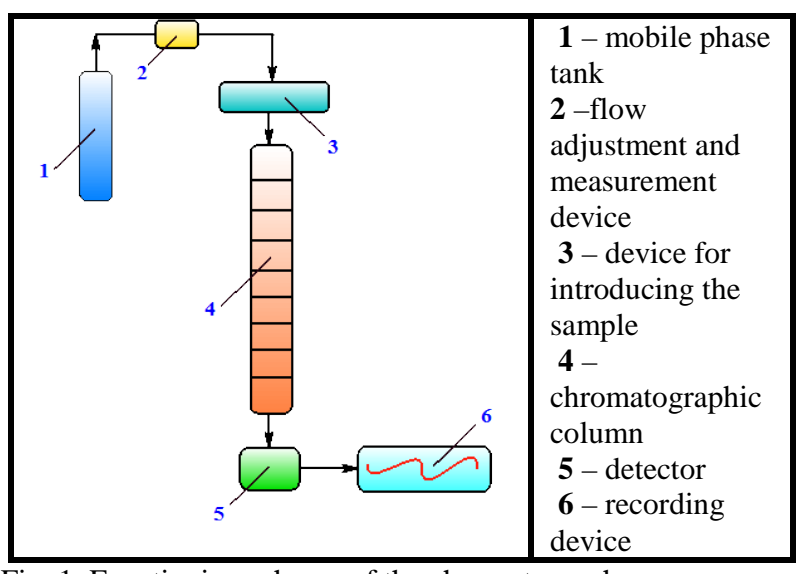

Fig. 1. Functioning scheme of the chromatograph

The results of the chromatographic analyses are presented in figures 2 and 3 . The identification of the pollutants in the water samples was performed according to the retention time compared to the retention time of a control saple.

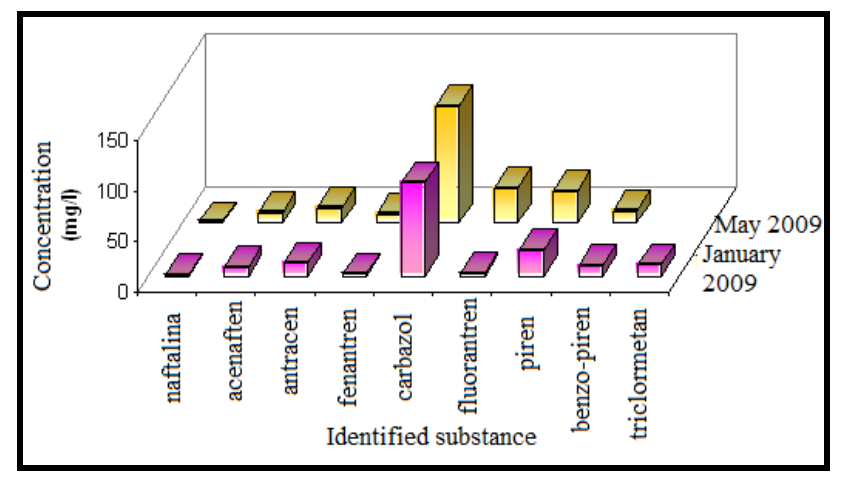

Fig. 2. Chromatographic analysis for the water sample no 1

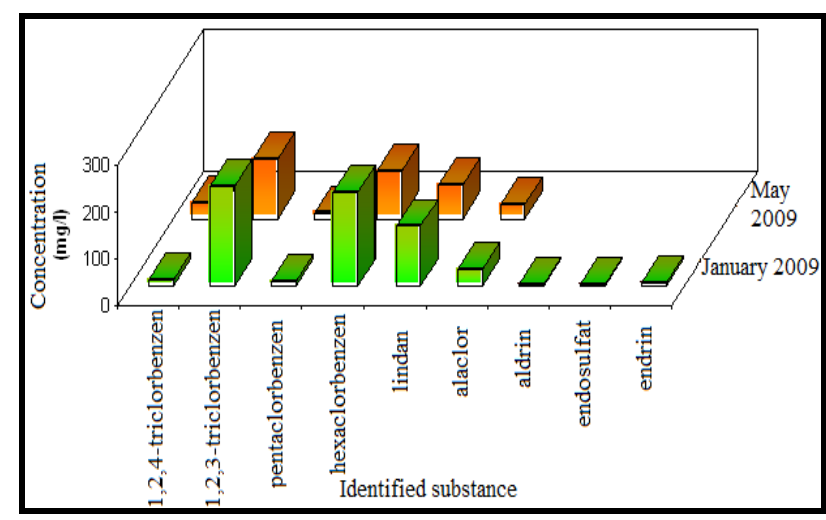

Fig. 3. Chromatographic analysis for the water sample no 2

The analysis shows the following facts:

- in the sample taken down the river from the chemical plant (Fig.2) about 25 compounds were identified, the highest concentrations being in the case of pesticides and insecticides, respectively semivolatili chlorinated organic compounds;

- in sample 2 (Fig. 3 - the cellulose factory), about 19 compounds were identified, the highest concentrations being recorded in the case of pesticides and insecticides.

\section{CONCLUSIONS}

The gas chromatography method is a performance method allowing the identification of a large range of pollutants. It enables us, better than other analysis methods, to decide on the proper wastewater treatment before discharging it into the river. In present study case, the polluted substances are mainly organochlorine pesticides, substances with harmful long-term effects. Additional treatment measures are required from the two industrial companies in order to clean theirs wastewater.

\section{REFERENCES}

Gerardi, M., H. (2003). The Microbiology of Anaerobic Digesters, John Wiley \& Sons, Inc, ISBN 0-471-20693-8

McNaught A.D., Wilkilson, A. (1997). Compendium of Chemical Terminology, $2^{\text {nd }}$ ed., Blackwell Science, ISBN 0865426848

Nascu, H. Jantschi, L. (2009). Analytical and Instrumental Chemistry, Academic Pres, ISBN (10) 973-744-046-3, Cluj

Pavia, D. L. and others (2006). Introduction to Organic Laboratory Techniques, Thomson Brooks/Cole ISBN 9780-495-28069-9

Stefanescu, G. (2003). Bioevolutie, Publisher Dacia, ISBN 97335-1597-3, Cluj-Napoca

*** (2010) http:// en.wikipedia.org/wiki, Chromatography 